\title{
Geometrical, electrical, and energetic parameters of hetero-disubstituted cumulenes and polyynes in the presence and absence of the external electric field
}

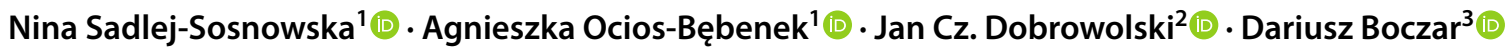

Received: 27 August 2021 / Accepted: 24 November 2021 / Published online: 20 December 2021

(c) The Author(s) 2021

\begin{abstract}
Cumulenes and polyynes have the potential to be applied as linear, $s p$-hybridized, one-dimensional all-carbon nanowires in molecular electronics and optoelectronics. The delocalization and conductivity descriptors of the two $\pi$-conjugated systems, heterodisubstituted with the $\mathrm{NO}_{2}, \mathrm{CN}, \mathrm{NH}_{2}$, and $\mathrm{OH}$ groups, were studied using the B3LYP, B3LYP/D3, CAM-B3LYP, and $\omega \mathrm{B} 97 \mathrm{XD}$ DFT functionals, combined with the aug-cc-pVTZ basis set. Three independent types of molecular descriptors, based on geometry (the HOMA index), electrical properties (trace of the polarizability tensor), and energetic (the HOMOLUMO energy gap) were shown to be mutually correlated and provided concordant indication that communication through the cumulene chain was considerably better than through the polyyne one. The communication can be tuned by using substituents of significantly different $\pi$-electron donor-acceptor properties as well as by the external electric field directed along the carbon chain.
\end{abstract}

Keywords Cumulenes $\cdot$ Polyynes $\cdot$ HOMA $\cdot$ Polarizability $\cdot$ Electric field

\section{Introduction}

Constructing efficient and stable molecular nano-devices is one of the urgent needs of material science oriented chemistry. Especially, factors determining the charge transport through the single-molecule junctions are essential for the development of sensors, thermoelectric devices, logic

Dariusz Boczar

d.boczar@nil.gov.pl

Nina Sadlej-Sosnowska

n.sadlej@nil.gov.pl

Agnieszka Ocios-Bębenek

a.ocios@nil.gov.pl

Jan Cz. Dobrowolski

j.dobrowolski@nil.gov.pl

1 Department of Synthetic Drugs, National Medicine Institute, 30/34 Chełmska Street, 00-725 Warsaw, Poland

2 Department of Drug Biotechnology and Bioinformatics, National Medicine Institute, 30/34 Chełmska Street, 00-725 Warsaw, Poland

3 Department of Antibiotics and Microbiology, National Medicine Institute, 30/34 Chełmska Street, 00-725 Warsaw, Poland operations, and information storage on molecular devices [1]. However, experimentally, it is hard to obtain unambiguous conductance data because of molecular flexibility which makes the geometry of the device fuzzy at the nanoscale. Hence, a great number of measurements must be compiled into a conductance histograms showing the distribution of the measured values [1]. This is why it is important to precede high-cost experimental research with less expensive, pilot, theoretical calculations.

Out of many classes of $\pi$-conjugated conducting organic materials, the one-dimensional $s p$-hybridized, linear molecules, such as polyynes and cumulenes, can find use as semiconducting nanowires for nanoelectronic devices [1, 2]. Cumulenes and polyynes are interesting moieties for molecular junctions because (i) the appropriate length of the molecules $(10-30 \AA)$ is close to the distance used in the scanning tunnelling microscopy, (ii) their rigidity and length-persistence allow for minimizing geometry fluctuations of the molecule within the junction, and (iii) it is relatively easy to avoid molecular aggregations and unwanted cross-linking between the units in the junctions [1].

The other applications of cumulenes and polyynes include optoelectronics $[1,3,4]$, since the $\pi$-electrons in conjugated systems are the source of large nonlinearity in the optical 
response of the material. These compounds exhibit electrochromism due to low operational driving voltage to change the colour and simultaneously guarantee high contrast and good reversibility of their redox states [1]. Cumulenes and polyynes can also be applied in organic light-emitting devices, liquid crystals, and photodynamic therapy [1]. The electronic and photophysical properties of these materials can be generally tuned by the substituent effect of the end groups, the number of conjugated units, and also by the possibility to functionalize them for connections with other device components such as metal clusters/tips, $\sigma$-bonded, or $\pi$-coordinated metal centres, which gives rise to the cumulene chain stabilization [5-7], as well as photosensitizers, ligands for target receptors, etc.

To purposely operate with design molecular elements for a device, it is rational to know the differences between the optional polyyne and cumulene elements to be able to control the device properties. Size, polarizability, $\pi$-electron delocalization, dipole moment, and HOMO-LUMO gap are among the most important properties useful to construct a molecular machine. The molecular wires bridging the junctions are designed to work under the electric field $[1,8,9]$. Therefore, the role of electric field influencing all above mentioned parameters [10-18] also needs to be considered. Action of an electric field on atoms or molecules can be measured and visualized with polarizability, being kind of a measure of the energy increment due to the dislocation of electron density within the molecule under the field. Polarizability is believed to play an important role in intermolecular interactions in heterogenous media such as protein-ligand binding [19-23].

This study is a continuation of our previous investigation on the susceptibility of two sets of $\pi$-electron conjugated molecules to perturbation in a uniform electric field [24]. One set was composed of deca-1,3,5,7,9-pentaenes and the other by $p$-diphenylbenzenes. The former core was terminated with $R_{1}$ and $R_{2}$ functional groups at the opposite ends, and the latter with the same, para positioned ones. Differences in the charge relocations in these conjugated molecules under the electric field revealed that the charge transfer was more efficient in the decapentaenes than in the $p$-diphenylbenzenes. Here, we are focusing on $s p$-hybridized polyynes and cumulenes [25-27] substituted at the two ends (Scheme 1) with two different groups of well-recognized $\pi$-electron donor-acceptor properties. A few years ago, we also inspected how the geometric aromaticity HOMA index varies within the group of unsubstituted cumulenes and polyynes with the increasing chain length [28]. Although the conductance of cumulenes increases with increasing length [8], the synthesis of long-chain cumulenes rises difficulties and [9]cumulenes are the longest derivatives that have been experimentally characterized to date $[1,25]$. It was also reported that cumulenes with odd number of CC bonds (even

$$
\begin{gathered}
\mathrm{R}_{1}-\mathrm{C} \equiv \mathrm{C}-\mathrm{C} \equiv \mathrm{C}-\mathrm{C} \equiv \mathrm{C}-\mathrm{C} \equiv \mathrm{C}-\mathrm{C} \equiv \mathrm{C}-\mathrm{R}_{2} \\
\text { polyyne }
\end{gathered}
$$<smiles>[R]C([R1])=C=C=C=C=C=C=C=C=C=C([R1])[2H]</smiles><smiles></smiles>

The electric field

Scheme 1 Disubstituted polyynes and cumulenes studied. $R_{1}, R_{2}=$ $\mathrm{NH}_{2}, \mathrm{OH}, \mathrm{CN}, \mathrm{NO}_{2}, \mathrm{R}_{1} \neq \mathrm{R}_{2}$ for the derivatives, and $\mathrm{R}_{1}=\mathrm{R}_{2}=\mathrm{H}$ for the unsubstituted forms

number of carbon atoms) exhibit higher conductance than the others, characterized by helical orbital structure $[1,25]$. Therefore, here we restricted our attention to [9]cumulenes and [9]polyynes, i.e., molecules containing ten carbon atoms and nine $\mathrm{CC}$ bonds in the main chain.

The aim of this computational study is three-fold: (i) to compare selected geometrical, electrical, and energetic parameters of two sets of analogous $\pi$-electron carbon chain structures containing ten carbon atoms: polyynes and cumulenes; (ii) to find which set of $\pi$-electron donor-acceptor properties of two substituents influences the molecular parameters the most; and (iii) to determine the influence of the electric field on the studied parameters. The calculations are done using four different DFT functionals combined with the aug-ccpVTZ basis set.

\section{Calculations}

The calculations were performed by using the Gaussian 09 revision D.01 suite of programs [29]. The geometries of the parent [9]cumulene $\left(\mathrm{C}_{10} \mathrm{H}_{4}\right.$, deca-1,2,3,4,5,6,7,8,9-nonaene), its four cis (Z), and four trans (E) 1,10-disubstituted derivatives, as well as the parent [9]polyyne $\left(\mathrm{C}_{10} \mathrm{H}_{2}\right.$, deca-1,3,5,7,9-pentayne) and its four 1,10-disubstituted disubstituted derivatives, were optimized with different DFT functionals, namely, B3LYP [30-32], CAM-B3LYP [33], and $\omega$ B97XD [34] and were combined with the aug-cc-pVTZ basis set $[35,36]$. The B3LYP functional was used with and without the D3 Grimme's correction for dispersion forces [37] to check whether these forces may have an impact on selected characteristics of the studied species. The CAM-B3LYP is the long-range-corrected version of B3LYP using the Coulomb-attenuating method [33] and here 
was used without $\mathrm{D} 3$ correction, while $\omega \mathrm{B} 97 \mathrm{XD}$ has the dispersion correction included by definition [34]. It includes the exact Hartree-Fock exchange in both short and long ranges and is effective in dealing with charge-transfer states [38, 39]. For non-covalent systems, $\omega B 97 X D$ performed slightly better than the other functionals, while much better for covalent systems and kinetics than many other dispersion-corrected functionals [34]. In our previous study of the substituent effect in the first excited singlet, first excited triplet, and cation-radical states [40-42], we considered the $\omega \mathrm{B} 97 \mathrm{XD}$ functional together with the B3LYP with and without Grimme's D3 dispersion forces correction and the CAM-B3LYP.

The harmonic frequencies of the optimized geometries were determined to be all positive to ascertain that the structures are true minima. To optimize the structure, the carbon chains were oriented strictly along the $O X$ axis. However, the optimization (for which nosymm key was applied) resulted in a very slight distortion of the carbon chain from the axis. The dipole moments and polarizabilities were calculated according to the algorithms defined in Gaussian 09. Polarizability values were converted to the CGS system unit $\AA^{3}\left(1\right.$ atomic unit $\left.=0.14818471 \AA^{3}\right)$. Calculations simulating the presence of the electric field were done using only the CAM-B3LYP functional. The field was directed along the $O X$ axis to which the optimized carbon chains remained almost perfectly parallel. The electric field values applied ranged from -0.010 to 0.010 a.u. ( -0.514 to $0.514 \mathrm{~V} / \mathrm{A}$ ). Correlation analysis was done using the SigmaPlot 13 program [43].

\section{Results and discussion}

[9] Cumulene (deca-1,2,3,4,5,6,7,8,9-nonaene), [9] polyyne (deca-1,3,5,7,9-pentayne), and their 1,10-heterodisubstituted derivatives (including both cis and trans cumulenes) were studied using different simple descriptors related to the communication between $\mathrm{C}_{1}$ and $\mathrm{C}_{10}$ ends. The descriptors include those based on the geometry of the carbon chains, electric parameters such as dipole moment or polarizability, and HOMO-LUMO energy gap as the energetic descriptor. The pairs of the chosen substituents were the following: $\mathrm{NO}_{2}$ and $\mathrm{NH}_{2}, \mathrm{NO}_{2}$ and $\mathrm{OH}, \mathrm{NO}_{2}$ and $\mathrm{CN}$, as well as $\mathrm{NH}_{2}$ and $\mathrm{OH}$, respectively. They have the following substituent electron donor-acceptor (EDA) properties [44]: $\mathrm{NO}_{2}$ is a strong $\pi$ acceptor, $\mathrm{CN}$ is weaker $\pi$ acceptor, $\mathrm{OH}$ is a $\pi$ donor, and $\mathrm{NH}_{2}$ is a strong $\pi$ donor; all the substituents are $\sigma$-acceptors. The $\sigma$ acceptor order is the following: $\mathrm{OH}, \mathrm{NH}_{2}, \mathrm{NO}_{2}, \mathrm{CN}$, i.e., sEDA = $-0.546,-0.451,-0.320$, and $-0.159 e$, respectively (sEDA is defined as the sum of occupancies of the $s, p_{x}$, and $p_{y}$ valence orbitals of all the ring $C$ atoms, where $x y$ is the ring plane of benzene molecule [44]). The $\pi$ donor-acceptor order is the following: $\mathrm{NH}_{2}, \mathrm{OH}, \mathrm{CN}, \mathrm{NO}_{2}$, i.e., $\mathrm{pEDA}=$ $+0.145,+0.121,-0.035,-0.069 e$, respectively (pEDA is defined as the sum of occupancies of the $p_{z}$ orbitals of all the ring $\mathrm{C}$ atoms contributing to the benzene $\pi$-electron system [44]). Thus, the $\left(\mathrm{NO}_{2} ; \mathrm{NH}_{2}\right)$ and $\left(\mathrm{NO}_{2} ; \mathrm{OH}\right)$ pairs are ( $\pi$-acceptor; $\pi$-donor) pairs, where the $\pi$-electron distribution is more polarized in the former than the latter, whereas $\left(\mathrm{NO}_{2} ; \mathrm{CN}\right)$ and $\left(\mathrm{NH}_{2} ; \mathrm{OH}\right)$ pairs are respectively ( $\pi$-acceptor; $\pi$-acceptor) and ( $\pi$-donor; $\pi$-donor).

Optimization shows that two conformers of cis-cumulenes substituted at one end with the $\mathrm{OH}$ group co-exist (Fig. 1). Total energies of these molecules indicated that the forms with the hydroxyl $\mathrm{H}$ atom directed towards $\mathrm{NH}_{2}$ or $\mathrm{NO}_{2}$ group (Fig. 1b, d, respectively) are more stable by ca. 2.3(2) $\mathrm{kcal} / \mathrm{mol}$ than the other conformers (Fig. 1a, c). The energy difference varies slightly with the functional used: from $2.376 \mathrm{kcal} / \mathrm{mol}(\mathrm{B} 3 \mathrm{LYP})$ to $2.516 \mathrm{kcal} / \mathrm{mol}(\omega \mathrm{B} 97 \mathrm{XD})$ for cis $-\mathrm{NH}_{2}, \mathrm{OH}$ and from $2.112 \mathrm{kcal} / \mathrm{mol}$ (B3LYP) to $2.209 \mathrm{kcal} /$ mol $(\omega \mathrm{B} 97 \mathrm{XD})$ for $c i s-\mathrm{NO}_{2}, \mathrm{OH}$. According to the Boltzmann distribution:

$\frac{n_{2}}{n_{1}}=\exp \left(-\frac{\Delta E}{R T}\right)$

where $n_{i}$ denotes the number of the $i$ th conformer, $R=$ $1.987 \mathrm{cal} \mathrm{mol}^{-1} \mathrm{~K}^{-1}$ is the universal gas constant, and $T$ denotes temperature assumed to be $298.15 \mathrm{~K}$, population of the dominating form is ca. $98 \%$.
Fig. 1 Equilibrium geometries of two conformations of cis- $\mathrm{NH}_{2}, \mathrm{OH}$ (a and b) and cis$\mathrm{NO}_{2}, \mathrm{OH}$ (c and d) cumulenes. Forms $\mathbf{b}$ and $\mathbf{d}$ were found to be the global conformers at all computational levels, and the data in the text refer only to these very conformers

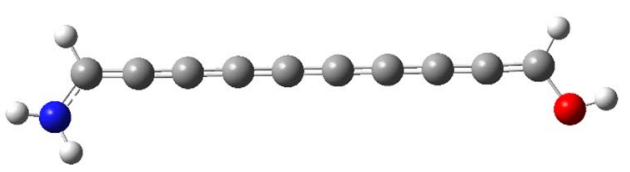

(a)

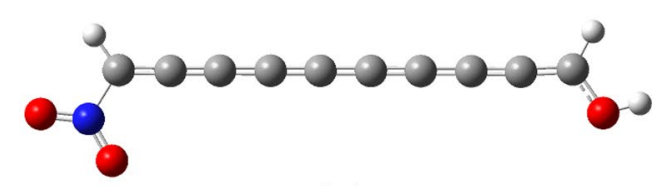

(c)

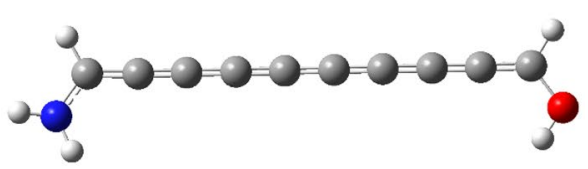

(b)

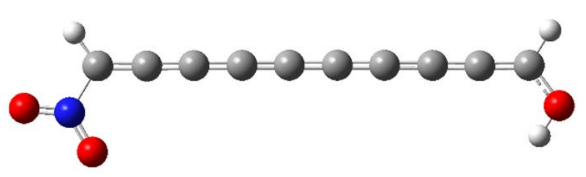

(d) 
Therefore, the less populated conformers were not analyzed further. In other cases when the different conformations could appear, frequency analysis either indicated that one of the forms is a transition state, or energetical analysis showed that its presence is not probable.

\section{The geometrical parameters: bond length alternation and the HOMA index}

The $\mathrm{CC}$ bond length in cumulenes and polyynes varies alternately (Fig. 2). For the communication between the $\mathrm{C}_{1}$ and $\mathrm{C}_{10}$ ends both the path length and the bond alternation at the path matter. On the one hand, the longer the path, the longer the "charge" trip, and on the other hand, the higher the alternation (variance of the bond lengths), the higher the barriers during the trip and the harder the communication between the $\mathrm{C}_{1}$ and $\mathrm{C}_{10}$ atoms. However, the Harmonic Oscillator Model of Aromaticity (HOMA) descriptor $[45,46]$ combines the size of the system and the bond alternation in one value, which was shown to be useful for the comparison of also acyclic, linear, or even branched structures [28, 47, 48]. For the unsaturated polymers such as polyenes or polythiophenes, the HOMA index seems to be a fair measure of the $\pi$-electron delocalization and thus to be a good simple tool for pre-evaluation of conductivity [28]. The HOMA index can be expressed as follows:

HOMA $=1-\frac{\alpha}{n} \sum_{i=1}^{n}\left(R_{i}-R_{\text {opt }}\right)^{2}$

where $R_{i}$ stands for the $i$ th bond length in the analyzed system, $R_{\text {opt }}$ is the CC bond length in the reference benzene ring determined/calculated with the same method as the system was, $n$ is the number of the $\mathrm{CC}$ bonds in the system, and $\alpha=257.7 \AA^{-2}$ is a normalization factor making the dimensionless HOMA index equal to 1 for perfectly aromatic benzene and 0 for a perfectly alternating hypothetical Kekulé cyclohexatriene ring. It was shown that the HOMA index can be treated as a general geometrical molecular descriptor which can adopt a wide range of values including negative ones for hydrocarbons [28, 47, 48]. Here, for aug-cc-pVTZ basis set combined with B3LYP, B3LYP/ D3, CAM-B3LYP, and $\omega$ B97XD functionals, the calculated $R_{\text {opt }}$ values were as follows: $1.3910,1.3913,1.3855$, and $1.3872 \AA$, respectively.

Inspection of the selected geometrical data (Tables 1 and S1) leads to the following conclusions. (i) The averaged bond length in cis and trans cumulenes is basically identical, while it is shorter in polyynes by $c a$. $0.01 \AA$. This gives $c a$. $0.1 \AA$ of difference in the total carbon chain length. (ii) The bond length alternation estimated as the standard deviation of the bond length is visibly smaller in cumulenes than in polyynes; namely, depending on the functional used, it ranges from 0.022 to $0.025 \AA$ for cumulenes vs. 0.066 to $0.079 \AA$ for polyynes. Thus, the path between the ends of the carbon chain in cumulenes is longer but smoother, while in polyynes is shorter but more "bumpy". (iii) The HOMA index as a measure of the structure delocalization is unequivocal: HOMA(cumulenes) $\approx-2.10 \gg \mathrm{HOMA}$ (polyynes) $\approx-3.65$ what indicates that the $\pi$-electron system in cumulenes is much more delocalized than in polyynes. Notice that the ideal delocalization is assumed for benzene for which HOMA $=1$. Hence, the HOMA index indicates much better communication/conductivity in cumulenes than in polyynes.

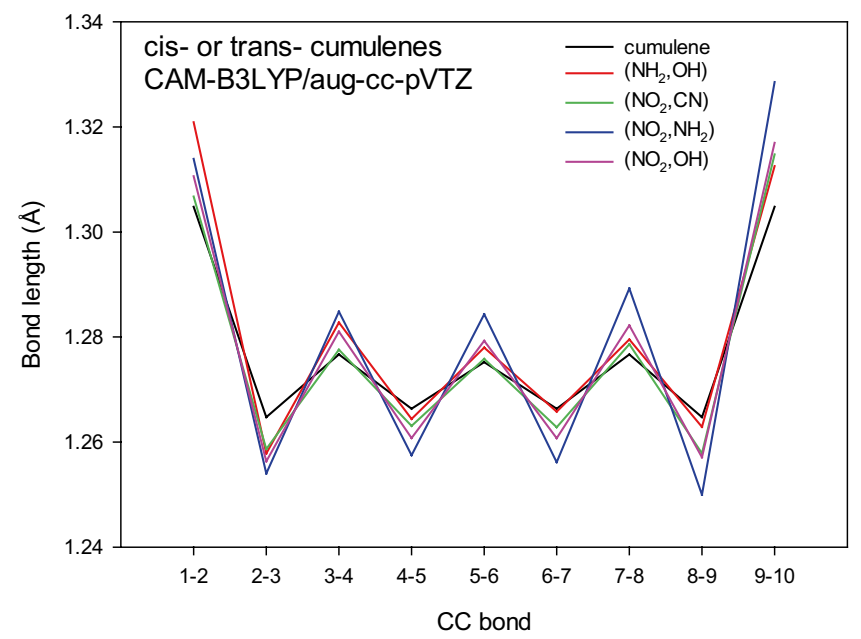

(a)

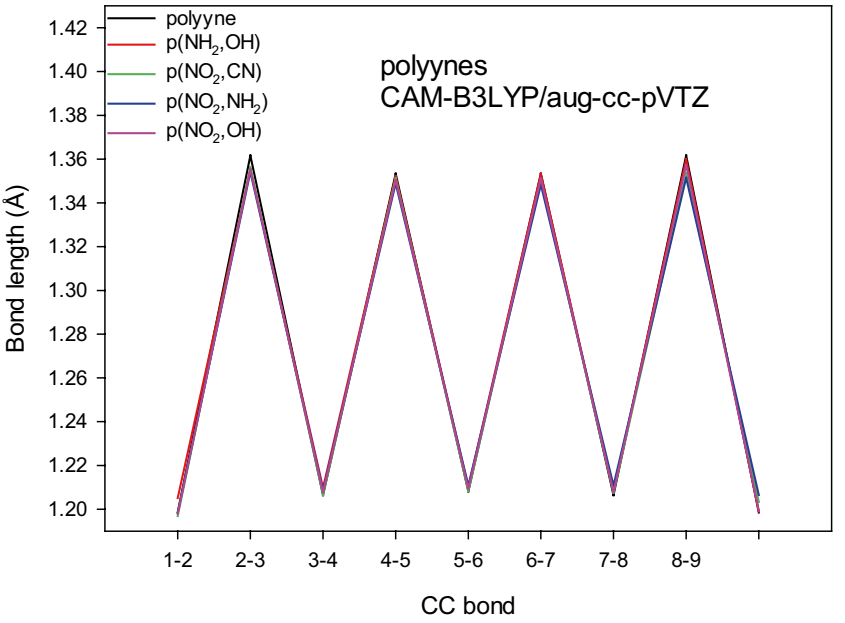

(b)

Fig. 2 Comparison of the CC bond lengths for the substituted cumulenes (a) and polyynes (b) calculated at the CAM-B3LYP/aug-cc-pVTZ level. The other functionals provide qualitatively the same result 
Table 1 Comparison of the geometrical characteristics of the studied cumulenes and polyynes. The compound names are abbreviated to cis- or trans- or py- with the substituent names, for cis and trans cumulenes and "py" for polyynes. B, D, C, and $\omega$ stand for the B3LYP, B3LYP/D3, CAM-B3LYP, and $\omega$ B97XD functionals, respectively. All calculations were done using the aug-cc-pVTZ basis set

\begin{tabular}{|c|c|c|c|c|c|c|c|c|c|c|c|c|}
\hline \multirow[t]{2}{*}{ Molecule } & \multicolumn{4}{|c|}{ Averaged bond length } & \multicolumn{4}{|c|}{$\begin{array}{l}\text { Bond length standard } \\
\text { deviation }\end{array}$} & \multicolumn{4}{|c|}{ HOMA } \\
\hline & B & $\mathrm{D}$ & $\mathrm{C}$ & $\omega$ & $\mathrm{B}$ & $\mathrm{D}$ & $\mathrm{C}$ & $\omega$ & B & $\mathrm{D}$ & $\mathrm{C}$ & $\omega$ \\
\hline um & 282 & 1.282 & 1.278 & 1.279 & 0.018 & 0.019 & 0.016 & 0.016 & -2.13 & -2.15 & -2.05 & -2.05 \\
\hline $\mathrm{s}-\mathrm{NH}_{2}, \mathrm{OH}$ & 1.285 & 1.285 & 1.281 & 1.282 & 0.025 & 0.025 & 0.022 & 0.022 & -2.04 & -2.06 & -1.95 & -1.95 \\
\hline cis- $\mathrm{NO}_{2}, \mathrm{CN}$ & 1.282 & 1.282 & 1.277 & 1.279 & 0.024 & 0.024 & 0.021 & 0.020 & -2.19 & -2.22 & -2.11 & -2.11 \\
\hline cis- $\mathrm{NO}_{2}, \mathrm{NH}_{2}$ & 1.284 & 1.284 & 1.280 & 1.281 & 0.030 & 0.030 & 0.028 & 0.027 & -2.14 & -2.17 & -2.06 & -2.05 \\
\hline cis- $\mathrm{NO}_{2}, \mathrm{OH}$ & 1.283 & 1.283 & 1.278 & 1.280 & 25 & 26 & 0.023 & 0.022 & -2.16 & -2.19 & -2.08 & -2.07 \\
\hline trans- $\mathrm{NH}_{2}, \mathrm{OH}$ & 1.285 & 1.285 & 1.281 & 1.282 & 0.025 & 0.025 & 0.022 & 0.022 & -2.04 & -2.06 & -1.95 & -1.95 \\
\hline trans- $\mathrm{NO}_{2}, \mathrm{CN}$ & 1.282 & 1.282 & 1.277 & 1.279 & 0.024 & 0.024 & 0.021 & 0.020 & -2.19 & -2.22 & -2.11 & -2.11 \\
\hline trans- $\mathrm{NO}_{2}, \mathrm{NH}_{2}$ & 1.284 & 1.284 & 1.280 & 1.281 & 0.030 & 0.030 & 0.028 & 0.027 & -2.14 & -2.17 & -2.06 & -2.05 \\
\hline trans- $\mathrm{NO}_{2}, \mathrm{OH}$ & 1.283 & 1.283 & 1.278 & 1.280 & 0.025 & 0.026 & 0.023 & 0.022 & -2.16 & -2.19 & -2.08 & -2.07 \\
\hline Polyyne & 1.273 & 1.273 & 1.272 & 1.274 & 0.068 & 0.068 & 0.081 & 0.081 & -3.65 & -3.67 & -3.83 & -3.82 \\
\hline py- $\mathrm{NH}_{2}, \mathrm{OH}$ & 1.274 & 1.274 & 1.273 & 1.274 & 0.065 & 0.065 & 0.079 & 0.078 & -3.51 & -3.54 & -3.70 & -3.70 \\
\hline py- $\mathrm{NO}_{2}, \mathrm{CN}$ & 1.272 & 1.271 & 1.270 & 1.272 & 0.063 & 0.063 & 0.078 & 0.078 & -3.57 & -3.60 & -3.81 & -3.81 \\
\hline py- $\mathrm{NO}_{2}, \mathrm{NH}_{2}$ & 1.272 & 1.272 & 1.271 & 1.273 & 0.060 & 0.060 & 0.076 & 0.076 & -3.47 & -3.50 & -3.70 & -3.70 \\
\hline py-NO ${ }_{2}, \mathrm{OH}$ & 1.272 & 1.272 & 1.271 & 1.272 & 0.064 & 0.064 & 0.079 & 0.079 & -3.60 & -3.63 & -3.81 & -3.81 \\
\hline
\end{tabular}

\section{The electrical parameters: polarizability and dipole moment}

Intuitively, polarizability and conductivity are related and the larger the one, the larger the another. However, in 2016, for some families of similar molecules, the conductance decreased as the molecular polarizability increased [49]. The study provided a rationale for the correlation between experimental conductance and calculated molecular polarizabilities. The use of a well-measurable molecular property such as polarizability could be an interesting descriptor of conductance. But, does this finding hold in the case of cumulenes and polyynes which are already used as the $s p$-carbon molecular wires [1]? To answer this question, we present polarizabilities and dipole moments calculated for all studied compounds (Tables S2 and S3).

First, notice that regardless of the functional used, the longitudinal polarizability, i.e., the $\alpha_{\mathrm{XX}}$ component of the polarizability tensor, where $O X$ axis is oriented in line with the carbon chain axis, strongly correlates with the polarizability trace, which is a measurable polarizability invariant (Fig. 3a). Second, observe that there is a trend suggesting that the higher the HOMA index of a cumulene or a polyyne carbon chain, the larger the polarizability trace (Fig. 3b). However, the differences of HOMA within a group of cumulenes and separately within a group of polyynes are small, and therefore, we can qualitatively conclude that the averaged polarizability of the group of studied cumulenes is higher than that of polyynes and the same applies for the averaged HOMA index. Observe also that the same substituents generate similar dipole moments in the cumulene or polyyne carbon chains (Fig. 3c). First, notice that the largest dipole moment is obtained when the ends are substituted with the most $\pi$-electron accepting $\mathrm{NO}_{2}$ and the most $\pi$-electron donating $\mathrm{NH}_{2}$ groups. The next large dipole moment is for the most $\pi$-electron accepting $\mathrm{NO}_{2}$ and the second strong $\pi$-electron donating OH group. Third, when the substituents have the same $\pi$-electron donor-acceptor properties $\left(\mathrm{NH}_{2}\right.$ and $\mathrm{OH}$ are both $\pi$-electron donors while $\mathrm{NO}_{2}$ and $\mathrm{CN} \pi$-electron acceptors $)$, the $\left(\mathrm{NH}_{2}, \mathrm{OH}\right)$ pair, which supplies the charge from the lone electron pairs to the $\pi$-electron system, generates larger dipole moment. Remember however that the influence of $\mathrm{NH}_{2}$ and $\mathrm{OH}$ groups on the $\sigma$-electron system can also be significant due to the difference in electronegativities of $\mathrm{N}$ and $\mathrm{O}$ atoms, or the difference in the sEDA values of the two groups. Still, the $\sigma$-electron effect is short-range and thus less important for the delocalized systems. In the studied carbon chains substitution with $\mathrm{NO}_{2}$ and $\mathrm{CN}$ is the least effective in producing the dipole moment (Fig. 3c).

There is no systematic correlation relating dipole moment and polarizability because they are independent electrical properties of the system (Fig. 3d). However, for the substituted carbon chain molecules, one can note some qualitative similarities which are easily seen in Fig. 3d. As for the dipole moments, the largest cumulene polarizabilities are obtained for the systems substituted with the $\mathrm{NO}_{2}$ and $\mathrm{NH}_{2}$ groups. Yet, the second large polarizability is observed for the systems ended by the $\mathrm{NO}_{2}$ and $\mathrm{CN}$ substituents (Fig. 3d). Next is the $\mathrm{NO}_{2}$ and $\mathrm{OH}$ groups, and then the $\mathrm{NH}_{2}$ and $\mathrm{OH}$ ones. The unsubstituted cumulene has the smallest polarizability. Interestingly, it is practically the same as the largest polarizability of substituted polyynes, i.e., the one substituted by the $\mathrm{NO}_{2}$ and $\mathrm{CN}$ groups. Then come the $\left(\mathrm{NO}_{2}, \mathrm{NH}_{2}\right)$ and $\left(\mathrm{NO}_{2}, \mathrm{OH}\right)$ pairs (Fig. 3d). As for the cumulenes, the 


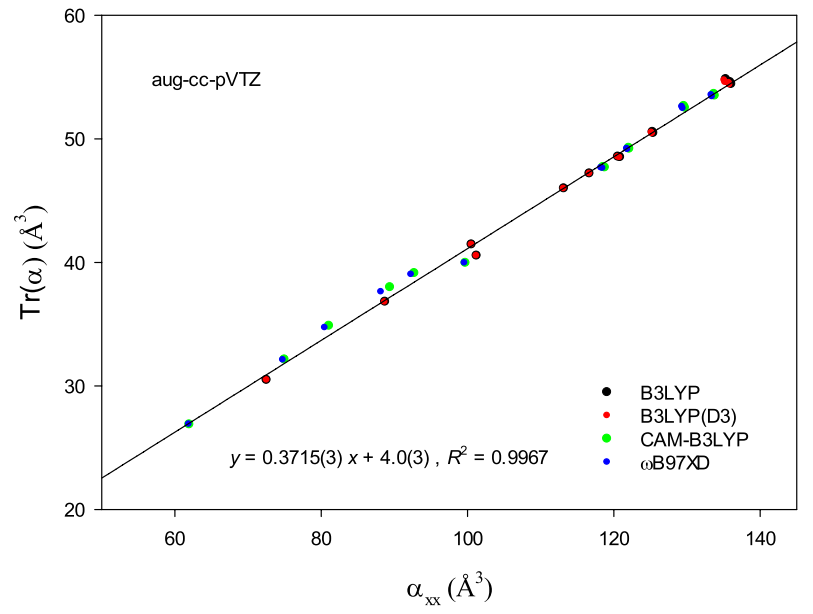

(a)

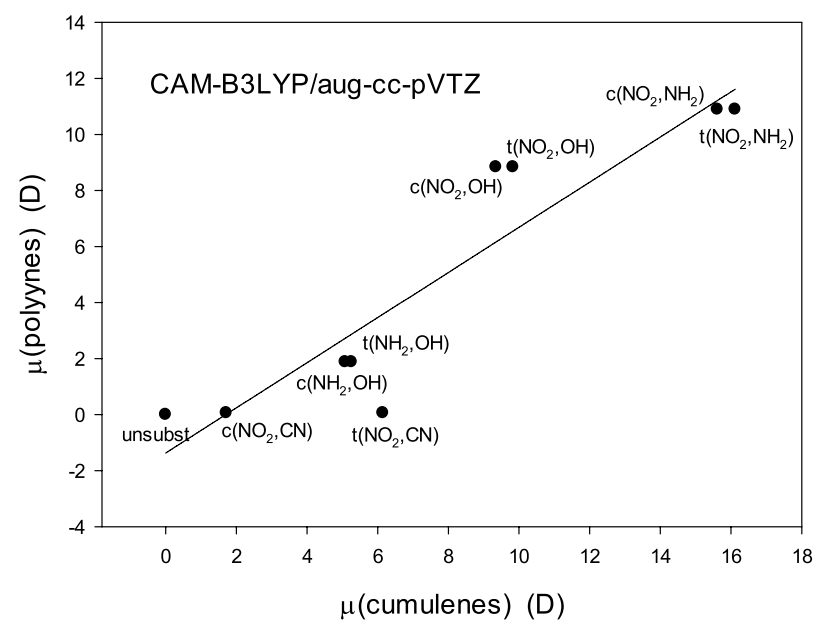

(c)

Fig. 3 a Linear correlation between $\alpha_{\mathrm{XX}}$ component and trace of the polarizability tensor $\operatorname{Tr}(\alpha)$ for the studied polyynes and cumulenes calculated using four different DFT functionals combined with the aug-cc-pVTZ basis set. The $O X$ axis is oriented in line with the carbon chain axis. b A scatter plot suggesting the trend that the greater aromaticity, the higher the polarizability trace in cumulenes and polyynes. c Linear correlation between the total dipole moments of sub-

$\mathrm{p}\left(\mathrm{NH}_{2}, \mathrm{OH}\right)$ molecule has the smallest polarizability within the substituted compounds and the unsubstituted polyyne has the smallest one.

\section{The HOMO-LUMO energy gap}

The HOMO-LUMO gap (presented in Table S4) is a major descriptor of the conducting ability of a molecule. The smaller the gap, the more conducting the molecule, and oppositely, the larger the gap, the more insulating it is. If we are interested to apply the carbon chains as conducting

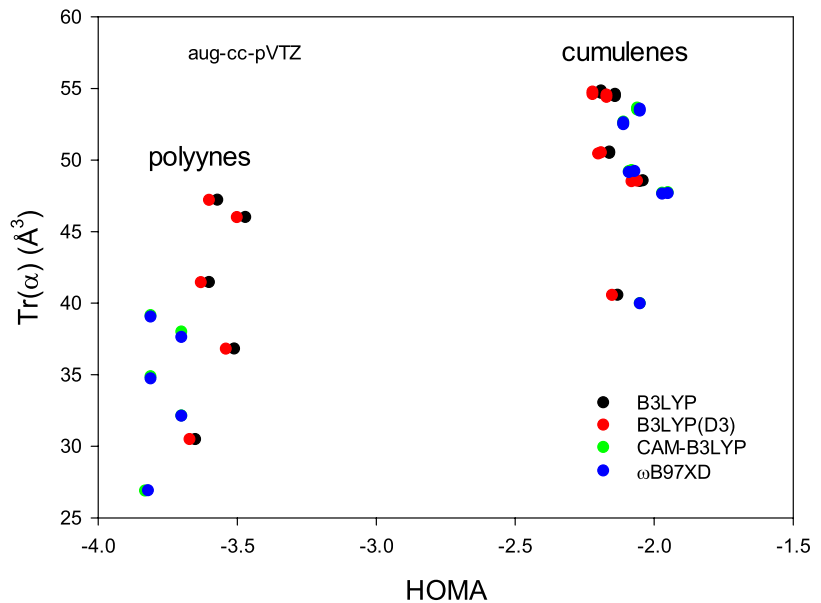

(b)

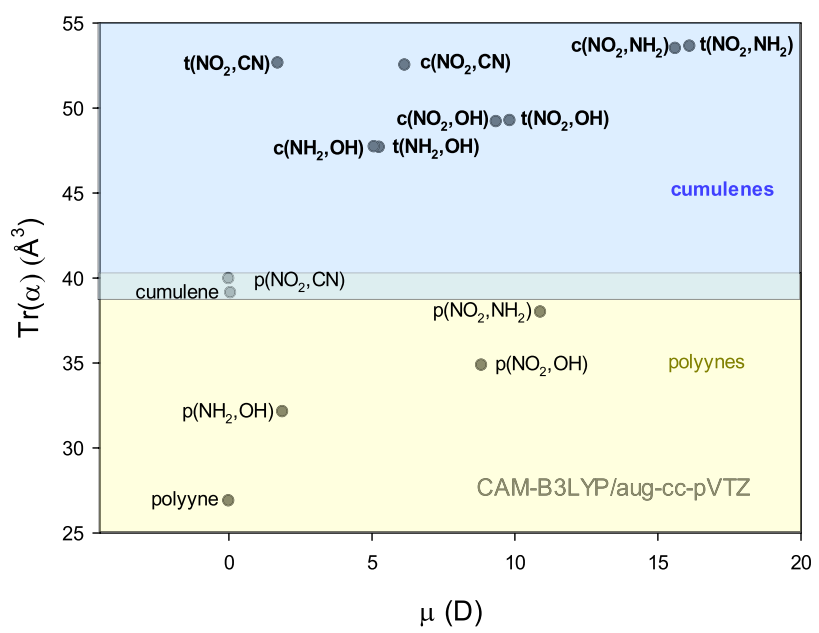

(d)

stituted cis (c) and trans (t) cumulenes and total dipole moments of polyynes. Substituents at the ends of the carbon chain are given in parentheses. d Differences in polarizability trace and dipole moment of the studied carbon chains. For clarity, the CAM-B3LYP/aug-ccpVTZ level was applied. The other functionals provide qualitatively the same result

molecular wires, we should know the factors decreasing the gap. A strong argument that for substituted polyynes and cumulenes the larger the trace of polarizability tensor, the smaller the gap, is presented in Fig. 4a. Indeed, significant non-linear correlations of the HOMO-LUMO gap with increasing polarizability trace are found using all four applied functionals combined with the aug-cc-pVTZ basis set. Thus, for polyynes and cumulenes, the decrease of conductance with the increase of polarizability, reported by Mazinani et al. [49], probably does not hold (Fig. 4a). Weak but significant trend between the HOMO-LUMO gap 


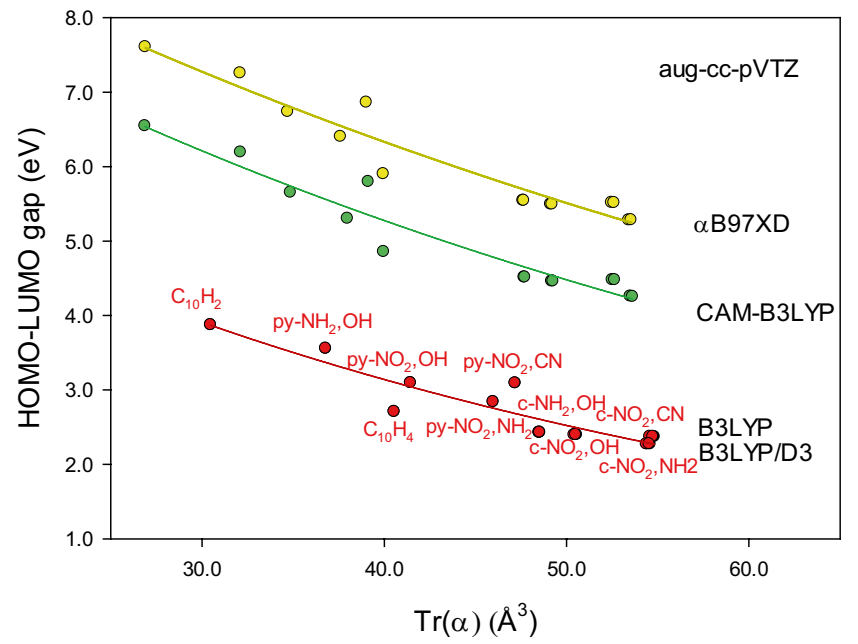

(a)

Fig. 4 a Correlations between energy of the HOMO-LUMO gap and trace of the polarizability tensor $\operatorname{Tr}(\alpha)$ for the studied polyynes and cumulenes calculated using four different DFT functionals combined with the aug-cc-pVTZ basis set. Data obtained by using the B3LYP

and the HOMA descriptor indicates larger conductivity of cumulenes than of polyynes because the larger the HOMA, a measure of the $\pi$-electron delocalization $[28,47]$, the smaller the gap (Fig. 4b).

Thus three independent descriptors, geometrical HOMA, electrical polarizability trace, and energetic HOMO-LUMO gap, concordantly indicate that delocalization and conductivity in cumulenes should be larger than that in polyynes. Moreover, out of the studied structures, the unsubstituted species are predicted to be the least delocalized and conductive, whereas the forms with $\mathrm{NO}_{2}$ and $\mathrm{NH}_{2}$ substituents at the opposite ends exhibit the largest delocalization and conductive abilities (Fig. 4).

\section{The influence of the electric field along the $O X$ axis on the conductive abilities}

Molecular wires composed of ca. $10 \AA$ long carbon chains bridge the junctions under electric field [1, 8]. Therefore, we inspected the influence of the electric field on the parameters characterizing the delocalization/conductive abilities. We simulated the presence of the electric fields from $c a$. -0.5 to $0.5 \mathrm{~V} / \AA$ (Fig. 5) directed along the carbon chain, i.e., the $\mathrm{OX}$ axis. The results of the calculations, restricted to the CAM-B3LYP functional, which was used in our previous work and yields qualitatively concordant results with all functionals applied here [24], are given in Tables S5, S6 and S7. Both orientations of the field vector were considered, so in one direction, the field vector was nearly concordant with the dipole moment direction, while in the other, the

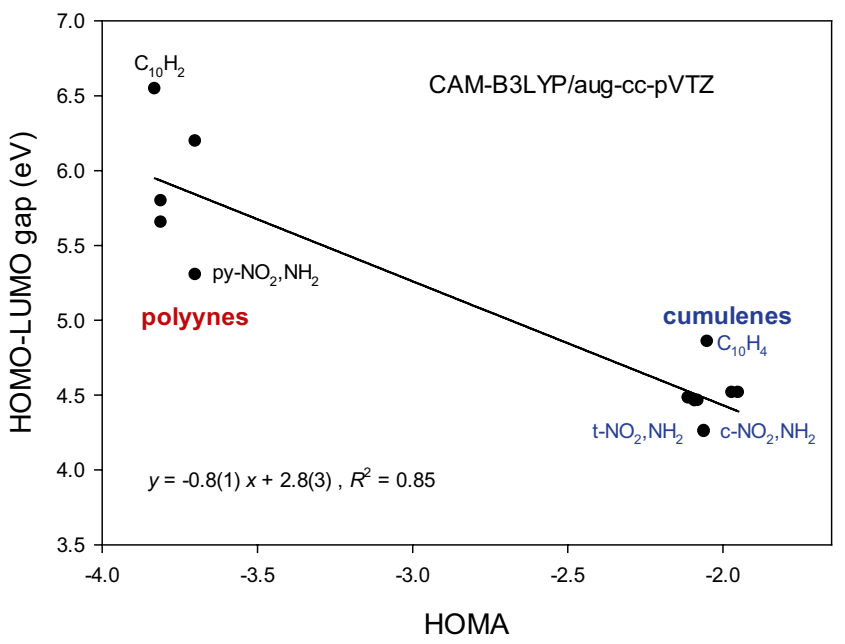

(b)

and B3LYP/D3 functionals overlap. b The correlation between energy of the HOMO-LUMO gap and the HOMA descriptor for the studied polyynes and cumulenes calculated using the CAM-B3LYP/ aug-cc-pVTZ method

dipoles were directed nearly oppositely. Notice that except for unsubstituted species and the polyyne substituted with $\left(\mathrm{NO}_{2}, \mathrm{CN}\right)$ pair of substituents, dipole moments of the studied molecules have the $Y$ and $Z$ components and are slightly distorted from the $O X$ axis (Table S2). The $Y$ and $Z$ components are produced by the direction of the lone pairs at the $\mathrm{OH}$ and $\mathrm{NH}_{2}$ groups, as well as the direction of the $\mathrm{H}$-atom in the $\mathrm{OH}$ group and the slight pyramidization of the $\mathrm{NH}_{2}$ substituent.

The changes of the studied descriptors in the external electric field are consistent and depend on the sign of $\mu_{x}$ : the $X$ component of the dipole moment. By convention, $\mu$ is defined as pointing from the negative to the positive charge. For the $\left(\mathrm{NO}_{2}, \mathrm{CN}\right),\left(\mathrm{NO}_{2}, \mathrm{OH}\right)$, and $\left(\mathrm{NO}_{2}, \mathrm{NH}_{2}\right)$ substituted molecules, $\mu_{x}$ is positive which means that the $\mathrm{NO}_{2}$ group is on the negative, while the other group is on the positive pole side. In contrast, the dipole moment of the $\left(\mathrm{NH}_{2}, \mathrm{OH}\right)$ substituted systems is negative (directed oppositely to the $\mathrm{OX}$ axis); i.e., the $\mathrm{NH}_{2}$ group is on the positive, while $\mathrm{OH}$ is on the negative pole side. So far, the poles discrimination played no role because the orientation of the $O X$ axis did not change the descriptor values. However, the presence of the electric field along the $O X$ axis and parallel to the carbon chain changes the descriptor values depend on the $\mu_{x}$ value and sign. In our calculations, the $\mathrm{NO}_{2}$ substituted molecules were oriented oppositely to the $\left(\mathrm{NH}_{2}, \mathrm{OH}\right)$ ones, and therefore, the appropriate straight lines of the latter increase when those for the $\mathrm{NO}_{2}$ compounds decrease, and conversely (Fig. 5). 


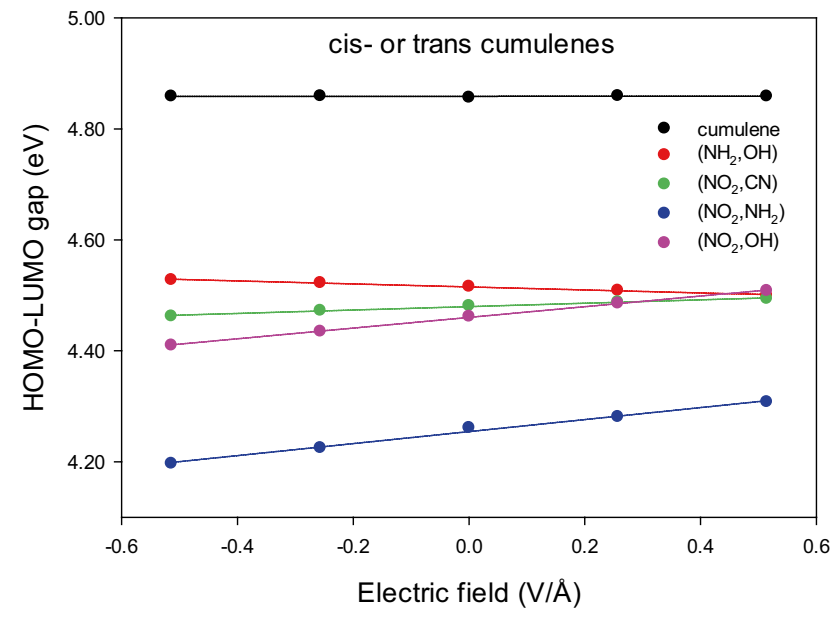

(a)

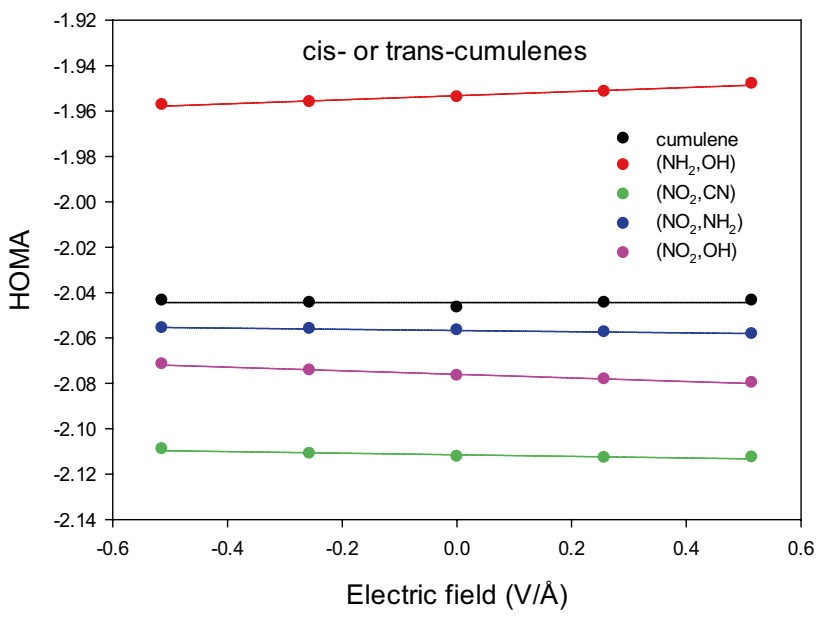

(c)

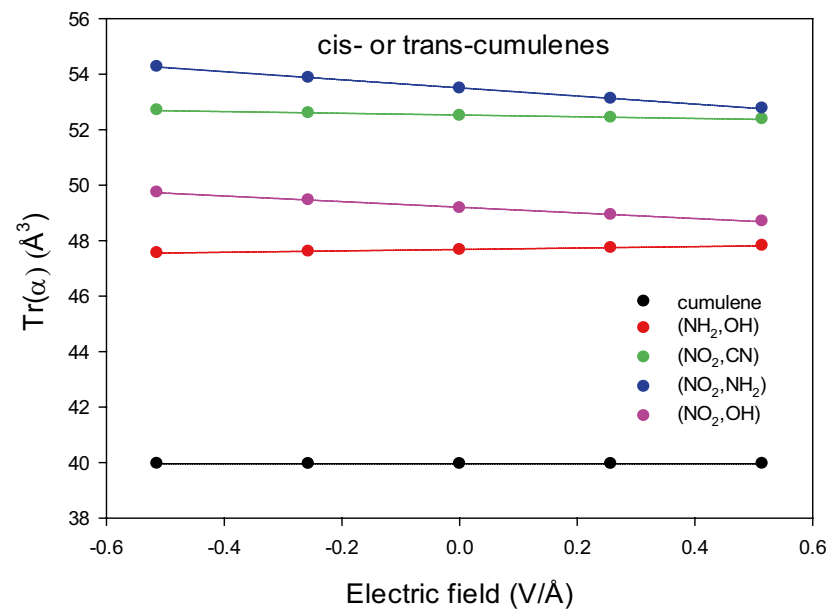

(e)

Fig. 5 The impact of the electric field intensity on HOMO-LUMO gap: a for cumulenes and b for polyynes, on HOMA index: $\mathbf{c}$ for cumulenes and $\mathbf{d}$ for polyynes, and on the trace of the polarizability

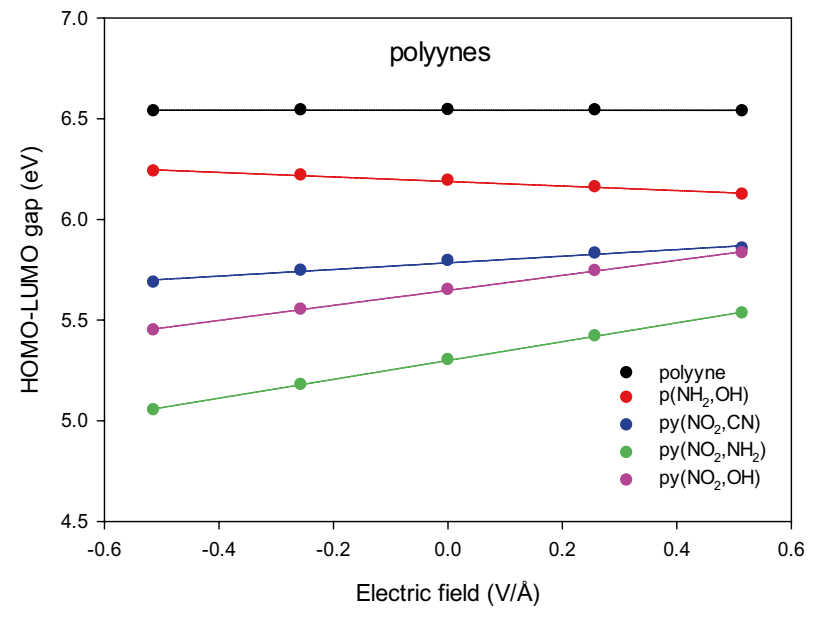

(b)

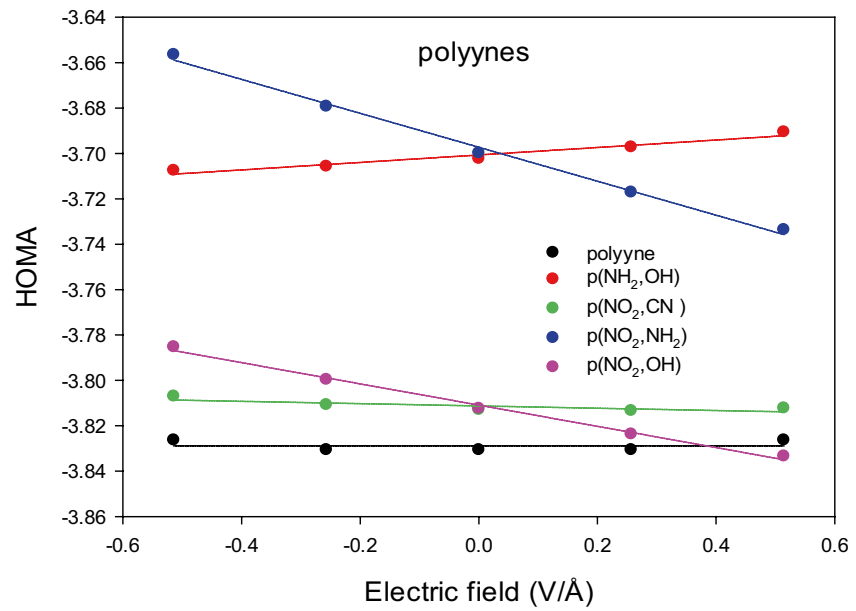

(d)

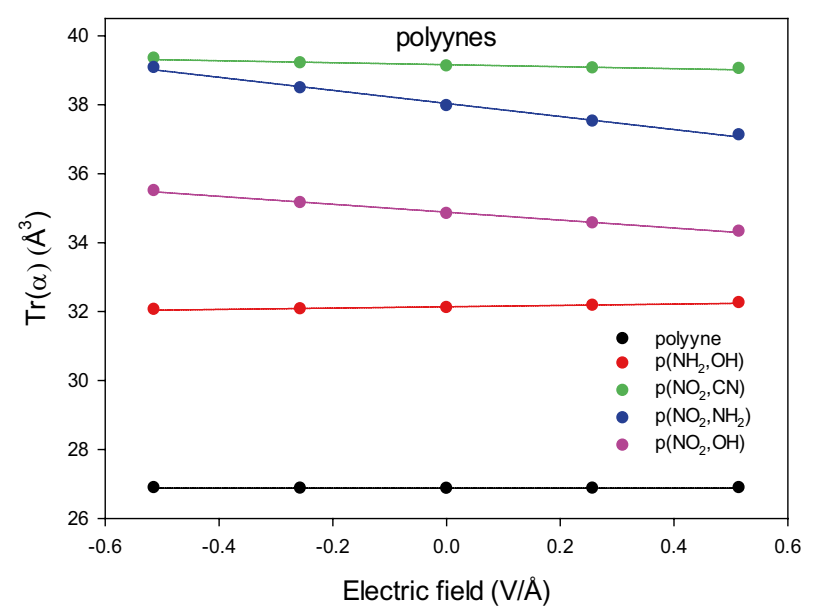

(f)

tensor: $\mathbf{e}$ for cumulenes and $\mathbf{f}$ for polyynes. All calculations were performed at the CAM-B3LYP/aug-cc-pVTZ level 
Table 2 Parameters of straight line fitting of the dependences of particular descriptors (HOMA, trace of polarizability tensor, HOMO-LUMO energy gap) on the electric field

\begin{tabular}{|c|c|c|c|c|c|c|c|c|c|}
\hline & \multicolumn{3}{|c|}{ cis-cumulenes } & \multicolumn{3}{|c|}{ trans-cumulenes } & \multicolumn{3}{|l|}{ polyynes } \\
\hline & $a$ & $b$ & $R^{2}$ & $a$ & $b$ & $R^{2}$ & $a$ & $b$ & $R^{2}$ \\
\hline & \multicolumn{9}{|c|}{ HOMO-LUMO gap } \\
\hline Unsubst. & $0.00(0)$ & $4.858(8)$ & ------- & $0.00(0)$ & $4.858(8)$ & ------- & $0.00(0)$ & $6.54(3)$ & - \\
\hline $\mathrm{NH}_{2}, \mathrm{OH}$ & $-0.02(7)$ & $4.515(4)$ & 0.991 & $-0.02(8)$ & $4.514(9)$ & 0.992 & $-0.11(2)$ & $6.18(9)$ & 0.986 \\
\hline $\mathrm{NO}_{2}, \mathrm{CN}$ & $0.03(1)$ & $4.479(6)$ & 0.988 & $0.03(1)$ & $4.479(1)$ & 0.990 & $0.1(7)$ & $5.78(6)$ & 0.974 \\
\hline $\mathrm{NO}_{2}, \mathrm{OH}$ & $0.09(6)$ & $4.460(2)$ & 0.999 & $0.09(6)$ & $4.461(6)$ & 0.999 & $0.37(4)$ & $5.64(9)$ & 0.999 \\
\hline \multirow[t]{2}{*}{$\mathrm{NO}_{2}, \mathrm{NH}_{2}$} & $0.10(8)$ & $4.25(4)$ & 0.992 & $0.11(0)$ & $4.254(2)$ & 1.000 & $0.46(8)$ & $5.30(0)$ & 1.000 \\
\hline & \multicolumn{9}{|c|}{ polarizability } \\
\hline Unsubst. & $0.00(0)$ & $39.96(1)$ & ------- & $0.00(0)$ & $39.96(1)$ & ------- & $0.00(0)$ & $26.88(3)$ & ----- \\
\hline $\mathrm{NH}_{2}, \mathrm{OH}$ & $0.2(6)$ & $47.68(6)$ & 0.991 & $0.2(6)$ & $47.72(2)$ & 0.994 & $0.1(9)$ & $32.1(4)$ & 0.939 \\
\hline $\mathrm{NO}_{2}, \mathrm{CN}$ & $-0.3(1)$ & $52.53(2)$ & 0.979 & $-0.3(1)$ & $52.64(9)$ & 0.997 & $-0.2(9)$ & $39.1(6)$ & 0.911 \\
\hline $\mathrm{NO}_{2}, \mathrm{OH}$ & $-1.0(1)$ & $49.2(1)$ & 0.998 & $-0.9(2)$ & $49.2(8)$ & 0.998 & $-1.1(5)$ & $34.8(9)$ & 0.995 \\
\hline \multirow[t]{2}{*}{$\mathrm{NO}_{2}, \mathrm{NH}_{2}$} & $-1.4(6)$ & $53.5(1)$ & 0.999 & $-1.3(0)$ & $53.6(5)$ & 0.999 & $-1.8(9)$ & $38.0(4)$ & 0.994 \\
\hline & \multicolumn{9}{|c|}{ HOMA } \\
\hline Unsubst. & $0.00(0)$ & $-2.044(4)$ & ------- & $0.00(0)$ & $-2.044(4)$ & ----- & $0.00(0)$ & $-3.82(9)$ & --- \\
\hline $\mathrm{NH}_{2}, \mathrm{OH}$ & $0.00(9)$ & $-1.953(2)$ & 0.965 & $0.00(9)$ & $-1.953(2)$ & 0.971 & $0.01(7)$ & $-3.700(7)$ & 0.952 \\
\hline $\mathrm{NO}_{2}, \mathrm{CN}$ & $-0.00(3)$ & $-2.111(0)$ & 0.750 & $-0.00(4)$ & $-2.111(5)$ & 0.795 & $-0.00(5)$ & $-3.811(3)$ & 0.637 \\
\hline $\mathrm{NO}_{2}, \mathrm{OH}$ & $-0.008(1)$ & $-2.076(2)$ & 0.972 & $-0.007(9)$ & $-2.076(0)$ & 0.982 & $-0.04(7)$ & $-3.810(9)$ & 0.994 \\
\hline $\mathrm{NO}_{2}, \mathrm{NH}_{2}$ & $-0.003(1)$ & $-2.057(1)$ & 0.948 & $-0.002(6)$ & $-2.056(7)$ & 0.970 & $-0.07(5)$ & $-3.69(7)$ & 0.995 \\
\hline
\end{tabular}

\section{Conclusions}

Polyynes and cumulenes are low-dimensional $s p$-hybridized linear all-carbon molecules of potential for being used as semiconducting nanowires in nanoelectronics. Therefore, it is important to understand the factors affecting the $\pi$-electron delocalization/conductivity properties in these compounds. Here, the influence of four substituents, of different $\pi$-electron donor-acceptor properties, on the $\pi$-electron delocalization/conductivity descriptors of [9]cumulene and [9]polyyne derivatives was studied using DFT calculations. The descriptors of geometrical, electrical, and energetical type were considered, namely, the average bond length, the bond length standard deviation, and the HOMA index; polarizability and dipole moment; and the HOMO-LUMO gap. We found that neither sole averaged bond length nor sole bond length standard deviation sufficiently defines the $\pi$-electron properties of the systems. The path between the ends of the carbon chain in cumulenes is longer than in polyynes, but the differences in the length of the adjacent carbon-carbon bonds are significantly higher in the latter group. Nevertheless, the increase of the HOMA (geometrical aromaticity as well as electron delocalization) index, defined for linear structures, significantly correlates with both the decrease of the HOMO-LUMO gap and the increase of polarizability. We also found that for the studied compounds, the decrease of the HOMO-LUMO gap significantly correlates of with the increase of the polarizability trace. This conclusion is in contradiction to Mazinani et al. [49] finding, which suggests that 
the relation between polarizability and conductivity strongly depends on the class of studied molecules. Three independent molecular descriptors, geometrical HOMA, electrical trace of the polarizability tensor, and energetic HOMO-LUMO energy gap, are all mutually correlated and concordantly indicate that cumulenes enable considerably better communication between the ends of the chain than polyynes. However, this property can be modified by using different substituents. The substituents applied have the following $\pi$-electron properties: $\mathrm{NO}_{2}$ is a strong $\pi$ acceptor, $\mathrm{CN}$ is weaker $\pi$ acceptor, $\mathrm{OH}$ is a $\pi$ donor, and $\mathrm{NH}_{2}$ is a strong $\pi$ donor. All substituents are $\sigma$-acceptors. Heterosubstitution with these groups yields the largest dipole moment for the $\left(\mathrm{NO}_{2}, \mathrm{NH}_{2}\right)$ pair and then for the $\left(\mathrm{NO}_{2}, \mathrm{OH}\right)$ one, i.e., for the substituents that differ the most. The smallest dipole is generated by the $\left(\mathrm{NO}_{2}, \mathrm{CN}\right)$ pair where the $\pi$-electron properties differ the least. The independent geometrical, electrical, and energetic molecular descriptors determined for cumulenes and polyynes can be moderated by the external electric field. If the positive pole of a molecule is directed towards the negative pole of the voltage source, the HOMO-LUMO gap decreases and polarizability increases the most for $\left(\mathrm{NO}_{2}, \mathrm{NH}_{2}\right)$ derivatives, then for $\left(\mathrm{NO}_{2}, \mathrm{OH}\right),\left(\mathrm{NO}_{2}, \mathrm{CN}\right)$ and next for $\left(\mathrm{NH}_{2}, \mathrm{OH}\right)$ ones, while the descriptors remain almost unaffected for the unsubstituted species. The presented results show the impact of the substituents and the external electric field on the descriptors related to carbon chain conductivity. They also suggest the qualitative way to maximize the desired properties of the $s p$ hybridized carbon chains.

Supplementary information The online version contains supplementary material available at https://doi.org/10.1007/s11224-021-01858-z.

\begin{abstract}
Author contribution N.S-S.: conceptualization, methodology, formal analysis, writing-original draft preparation; A.O-B.: visualization, writing - review and editing; J. Cz. D.: methodology, formal analysis, visualization, writing — original draft preparation, writing—review and editing; D.B.: formal analysis, visualization, writing — original draft preparation, writing-review and editing. All authors have read and agreed to the published version of the manuscript.
\end{abstract}

Funding This study was supported by the National Medicines Institute based on financial support of the Polish Ministry of Science and Higher Education for the statutory activity of NMI. The computational Grants: G44-18 from the Interdisciplinary Center for Mathematical and Computer Modelling (ICM) of Warsaw University (for N.S.-S.) and from the Świerk Computing Centre (CIŚ) (for J. Cz. D.) are also received.

\section{Declarations}

Ethics approval Not applicable.

Consent to participate Not applicable.

Consent for publication Not applicable.

Conflict of interest The authors declare no competing interests.
Open Access This article is licensed under a Creative Commons Attribution 4.0 International License, which permits use, sharing, adaptation, distribution and reproduction in any medium or format, as long as you give appropriate credit to the original author(s) and the source, provide a link to the Creative Commons licence, and indicate if changes were made. The images or other third party material in this article are included in the article's Creative Commons licence, unless indicated otherwise in a credit line to the material. If material is not included in the article's Creative Commons licence and your intended use is not permitted by statutory regulation or exceeds the permitted use, you will need to obtain permission directly from the copyright holder. To view a copy of this licence, visit http://creativecommons.org/licenses/by/4.0/.

\section{References}

1. Bryce MR (2021) A review of functional linear carbon chains (oligoynes, polyynes, cumulenes) and their applications as molecular wires in molecular electronics and optoelectronics. J Mat Chem C 9:10524-10546. https://doi.org/10.1039/D1TC01406D

2. Alkorta I, Elguero J (2005) Polyynes vs. cumulenes: their possible use as molecular wires. Struct Chem 16:77-79. https://doi.org/10. 1007/s11224-005-1089-9

3. Kutrovskaya S, Osipov A, Baryshev S, Zasedatelev A, Samyshkin V, Demirchyan S, Pulci O, Grassano D, Gontrani L, Hartmann RR, Portnoi ME, Kucherik A, Lagoudakis PG, Kavokin A (2020) Excitonic fine structure in emission of linear carbon chains. Nano Lett 20:6502-6509. https://doi.org/10.1021/acs.nanolett.0c02244

4. Silveirinha MG, Alù A, Li J, Engheta N (2008) Nanoinsulators and nanoconnectors for optical nanocircuits. J Appl Phys 103:064305. https://doi.org/10.1063/1.2891423

5. Aguirre-Etcheverry P, O'Hare D (2010) Electronic communication through unsaturated hydrocarbon bridges in homobimetallic organometallic complexes. Chem Rev 110:4839-4864. https://doi. org $/ 10.1021 / \mathrm{cr} 9003852$

6. Gleiter R, Werz DB (2010) Alkynes between main group elements: from dumbbells via rods to squares and tubes. Chem Rev 110:4447-4488. https://doi.org/10.1021/cr9003727

7. Cadierno V, Gimeno J (2009) Allenylidene and higher cumulenylidene complexes. Chem Rev 109:3512-3560. https://doi.org/ $10.1021 / \mathrm{cr} 8005476$

8. Zang Y, Fu T, Zou Q, Ng F, Li H, Steigerwald ML, Nuckolls C, Venkata-raman L (2020) Cumulene wires display increasing conductance with increasing length. Nano Lett 20:8415-8419. https://doi.org/10.1021/acs.nanolett.0c03794

9. Zang Y, Zou Q, Fu T, Ng F, Fowler B, Yang J, Li H, Steigerwald ML, Nuckolls C, Venkataraman L (2019) Directing isomerization reactions of cumulenes with electric fields. Nat Commun 10:4482. https://doi.org/10.1038/s41467-019-12487-w

10. Sowlati-Hashjin S, Matta CF (2013) The chemical bond in external electric: Energies, geometries, and vibrational Stark shifts of diatomic molecules. J Chem Phys 139:144101. https://doi.org/10. $1063 / 1.4820487$

11. Shaik S, Ramanan R, Danovich D, Mandal D (2018) Structure and reactivity/selectivity control by oriented-external electric fields. Chem Soc Rev 47:5125-5145. https://doi.org/10.1039/C8CS00354H

12. Enchev V, Monev V, Markova N, Rogozherov M, Angelova S, Spassova M (2013) A model system with intramolecular hydrogen bonding: effect of external electric field on the tautomeric conversion and electronic structures. Comp Theor Chem 1006:113-122. https://doi.org/10.1016/j.comptc.2012.11.021

13. Park ES, Boxer SG (2002) Origins of sensitivity of molecular vibrations to electric fields: carbonyl and nitrosyl stretches in 
model compounds and proteins. J Phys Chem B 106:5800-5806. https://doi.org/10.1021/jp0203043

14. Dominikowska J, Krygowski TM, Ozimiński WP, Palusiak M (2015) Aromaticity induced by electric field: the case of polycalicenes. J Org Chem 80:9091-9101. https://doi.org/10.1021/acs. joc. 5 b01441

15. Dominikowska J, Palusiak M (2018) Tuning aromaticity of parasubstituted benzene derivatives with an external electric field. ChemPhysChem 19(5):590-595. https://doi.org/10.1002/cphc. 201701203

16. Shaik S, de Visser SP, Kumar D (2004) External electric field will control the selectivity of enzymatic-like bond activations. J Am Chem Soc 126:11746-11749. https://doi.org/10.1021/ja047432k

17. Ciampi S, Darwish N, Aitken HM, Diez-Pérez I, Coote ML (2018) Harnessing electrostatic catalysis in single molecule, electrochemical and chemical systems: a rapidly growing experimental tool box. Chem Soc Rev 47:5146-5164. https://doi.org/10.1039/ C8CS00352A

18. Arabi AA, Matta CF (2011) Effects of external electric fields on double proton transfer kinetics in the formic acid dimer. Phys Chem Chem Phys 13:13738-13748. https://doi.org/10.1039/ C1CP20175A

19. Laidig KE, Bader RFW (1990) Properties of atoms in molecules: atomic polarizabilities. J Chem Phys 93:7213-7224. https://doi. org/10.1063/1.459444

20. Truchon J-F, Nicholls A, Iftimie RI, Roux B, Bayly CI (2008) Accurate molecular polarizabilities of continuum electrostatics. J Chem Theor Comput 4:1480-1493. https://doi.org/10.1021/ ct $800123 \mathrm{c}$

21. Darling CL, Schlegel HB (1994) Dipole moments, polarizabilities, and infrared intensities calculated with electric field dependent functions. J Phys Chem 98:5855-5861. https://doi.org/10.1021/ j100074a008

22. Gough KM, Yacowar MM, Cleve RH, Dwyer JR (1996) Analysis of molecular polarizabilities and polarizability derivatives in $\mathrm{H}_{2}$, $\mathrm{N}_{2}, \mathrm{~F}_{2}, \mathrm{CO}$, and HF, with the Theory of Atoms in Molecules. Can J Chem 74:1139-1144. https://doi.org/10.1139/v96-128

23. Hickey AL, Rowley CN (2014) Benchmarking quantum chemical methods for the calculation of molecular dipole moments and polarizabilities. J Phys Chem A 118:3678-3687. https://doi.org/ 10.1021/jp502475e

24. Sadlej-Sosnowska N (2019) The response of electronic and energetic properties of conjugated vs aromatic molecules to an external uniform electric field. Struct Chem 30:1407-1413. https://doi. org/10.1007/s11224-019-01345-6

25. Garner MH, Bro-Jørgensen W, Pedersen PD, Solomon GC (2018) Reverse bond-length alternation in cumulenes: candidates for increasing electronic transmission with length. J Phys Chem C 122:26777-26789. https://doi.org/10.1021/acs.jpcc.8b05661

26. Milani A, Barbieri V, Facibeni A, Russo V, Li Bassi A, Lucotti A, Tommasini M, Tzirakis MD, Diederich F, Casari CS (2019) Structure modulated charge transfer in carbon atomic wires. Sci Rep 9:1648. https://doi.org/10.1038/s41598-018-38367-9

27. Gunasekaran S, Hernangómez-Pérez D, Davydenko I, Marder S, Evers F, Venkataraman L (2018) Near length independent conductance in polymethine molecular wires. Nano Lett 18:63876391. https://doi.org/10.1021/acs.nanolett.8b02743

28. Dobrowolski JC, Ostrowski S (2015) On the HOMA index of some acyclic and conducting systems. RSC Adv 5:9467-9471. https://doi.org/10.1039/C4RA15311A

29. Frisch MJ, Trucks GW, Schlegel HB, Scuseria GE, Robb MA, Cheeseman JR, Scalmani G, Barone V, Mennucci B, Petersson GA et al (2013) Gaussian 09, revision D.01. Gaussian Inc.: Wallingford, CT
30. Becke AD (1993) Density-functional thermochemistry. III. The role of exact exchange. J Chem Phys 98:5648. https://doi.org/10. 1063/1.464913

31. Lee C, Yang W, Parr RG (1988) Development of the Colle-Salvetti correlation-energy formula into a functional of the electron density. Phys Rev B 37:785-789. https://doi.org/10.1103/PhysRevB. 37.785

32. Stephens PJ, Devlin FJ, Chabalowski CF, Frisch MJ (1994) $\mathrm{Ab}$ initio calculation of vibrational absorption and circular dichroism spectra using density functional force fields. J Phys Chem 98:11623-11627. https://doi.org/10.1021/j100096a001

33. Yanai T, Tew D, Handy N (2004) A new hybrid exchange-correlation functional using the Coulomb-attenuating method (CAM-B3LYP). Chem Phys Lett 393:51-57. https://doi.org/10.1016/j.cplett.2004. 06.011

34. Chai JD, Head-Gordon M (2009) Long-range corrected doublehybrid density functionals. J Chem Phys 131:174105. https://doi. org/10.1063/1.3244209

35. Kendall RA, Dunning TH, Harrison RJ (1992) Electron affinities of the first-row atoms revisited. Systematic basis sets and wave functions. J Chem Phys 96:6796-6806. https://doi.org/10.1063/1. 462569

36. Woon DE, Dunning TH (1993) Gaussian basis sets for use in correlated molecular calculations. III. The atoms aluminum through argon. J Chem Phys 98:1358-1371. https://doi.org/10.1063/1. 464303

37. Grimme S (2006) Semiempirical GGA-type density functional constructed with a long-range dispersion correction. J Comput Chem 27:1787-1799. https://doi.org/10.1002/jcc.20495

38. Sinnecker S, Neese F (2006) Spin-spin contributions to the zerofield splitting tensor in organic triplets, carbenes and biradicals-a density functional and ab initio study. J Phys Chem A 110:1226712275. https://doi.org/10.1021/jp0643303

39. Ou Q, Subotnik JE (2013) Electronic relaxation in benzaldehyde evaluated via TD-DFT and localized diabatization: intersystem crossings, conical intersections, and phosphorescence. J Phys Chem C 117:19839-19849. https://doi.org/10.1021/jp405574q

40. Dobrowolski JC, Lipiński PFJ, Karpińska G (2018) Substituent effect in the first excited singlet state of monosubstituted benzenes. J Phys Chem A 122:4609-4621. https://doi.org/10.1021/ acs.jpca.8b02209

41. Dobrowolski JC, Karpińska G (2020) Substituent effect in the first excited triplet state of monosubstituted benzenes. ACS Omega 5:9477-9490. https://doi.org/10.1021/acsomega.0c00712

42. Dobrowolski JC, Dudek WM, Karpińska G, Baraniak A (2021) Substituent effect in the cation radicals of monosubstituted benzene. Int J Mol Sci 22:6936. https://doi.org/10.3390/ijms22136936

43. SigmaPlot 13 (2017) Systat Software, San Jose, California, USA, https://www.systatsoftware.com Accessed 14 Dec 2021

44. Ozimiński WP, Dobrowolski JC (2009) $\sigma$ - and $\pi$-electron contributions to the substituent effect: natural population analysis. J Phys Org Chem 22:769-778. https://doi.org/10.1002/poc.1530

45. Kruszewski J, Krygowski TM (1972) Definition of aromaticity basing on the harmonic oscillator model. Tetrahedron Lett 13:3839-3842. https://doi.org/10.1016/S0040-4039(01)94175-9

46. Szatylowicz H, Wieczorkiewicz PA, Krygowski TM (2021) Molecular geometry as a source of electronic structure of $\pi$-electron systems and their physicochemical properties. Chapter 3, pp. 71-99, in Aromaticity: modern computational methods and applications. I. Fernández (Ed.) Elsevier. https://doi.org/10. 1016/B978-0-12-822723-7.00003-0

47. Ostrowski S, Dobrowolski JC (2014) What does the HOMA index really measure? RSC Adv 4:44158-44161. https://doi.org/10. 1039/C4RA06652A 
48. Dobrowolski JC (2019) Three queries about the HOMA index. ACS Omega 4:18699-18710. https://doi.org/10.1021/acsomega. 9b02628

49. Mazinani SKS, Meidanshahi RV, Palma JL, Tarakeshwar P, Hansen T, Ratner MA, Mujic V (2016) Polarizability as a molecular descriptor for conductance in organic molecular circuits. $\mathrm{J}$
Phys Chem C 120:26054-26060. https://doi.org/10.1021/acs.jpcc. $6 \mathrm{~b} 06241$

Publisher's note Springer Nature remains neutral with regard to jurisdictional claims in published maps and institutional affiliations. 